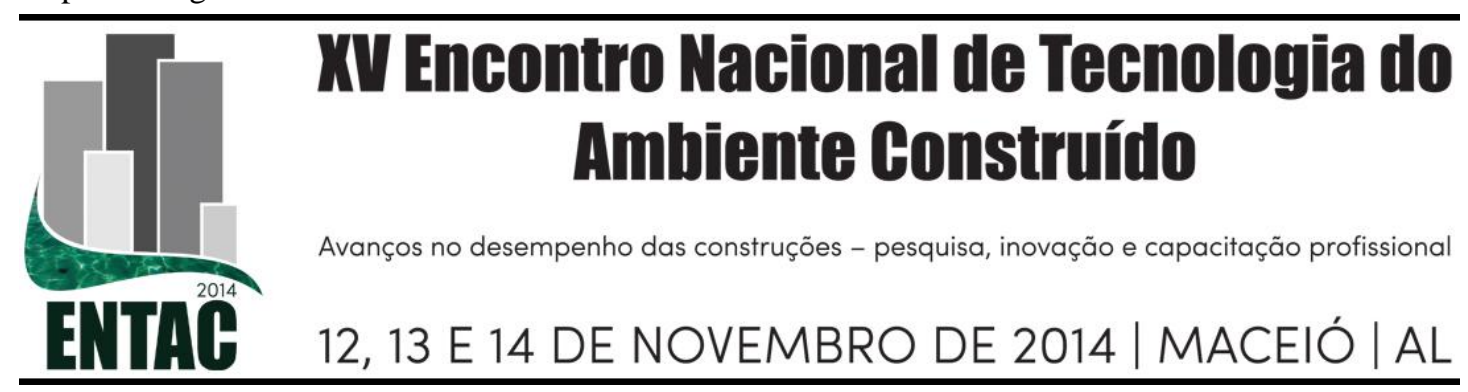

\title{
DISPONIBILIDADE DE LUZ NATURAL NO INTERIOR DO AMBIENTE NO LITORAL NORTE DE MACEIÓ - AL
}

\author{
LIMA, Renata Camelo (1); CABÚS, Ricardo Carvalho (2) \\ (1) Universidade Federal de Alagoas - UFAL, e-mail: renatacamelo.arq@gmail.com \\ (2) Universidade Federal de Alagoas - UFAL, e-mail: ricardo.cabus@gmail.com
}

\begin{abstract}
RESUMO
Mediante a necessidade de conservação de energia, a iluminação natural destaca-se principalmente por reduzir o uso da energia elétrica na edificação, através da integração com sistemas de iluminação artificial e dos dispositivos de controle associados. Surge assim uma maior preocupação com a eficiência energética nos edifícios através da sua adaptação às condições climáticas do local e a garantia de acesso à luz solar no meio urbano. Tendo em vista que a altura das edificações obstruidoras e a largura e orientação da via podem influenciar na disponibilidade de luz natural no interior das edificações, este estudo objetivou analisar a interferência do entorno construído na disponibilidade de luz natural no interior de edifícios multifamiliares no litoral norte de Maceió, a partir de parâmetros estabelecidos pela regulamentação urbana. O presente trabalho trata-se de um estudo exploratório que compõe uma dissertação de mestrado em andamento. A metodologia adotada consistiu em um estudo de caso, que utilizou a simulação no software TropLux 6 para estudar a influência do conjunto de variáveis, relacionadas ao entorno das edificações no espaço urbano. Entre os resultados obtidos, verificou-se que a presença da edificação obstruidora pode diminuir em até $40 \%$ a iluminância global média no ambiente orientado para oeste e acarretar uma diminuição de pelo menos $15 \%$ no espaço orientado para o sul. Estes dados demonstram que dependendo dos parâmetros adotados, as edificações obstruidoras podem afetar negativamente o nível de iluminância no interior do ambiente. Portanto, as regulamentações urbanas da cidade de Maceió devem contemplar de maneira mais específica o aproveitamento dos recursos naturais, como a luz natural, a fim de promover a diminuição do consumo energético por parte dos sistemas artificiais de iluminação principalmente nas áreas urbanas mais adensadas.
\end{abstract}

Palavras-chave: Iluminação natural, Verticalização, Espaço Urbano.

\begin{abstract}
Under the pretext of the need for energy conservation, natural lighting stands out for reducing the use of electricity in the building, through integration with artificial lighting systems and associated control devices. This leads to a greater concern with energy efficiency in buildings through its adaptation to the local weather conditions and ensuring access to sunlight in the urban environment. Given that the height of the surrounding buildings and street width and orientation can influence the availability of natural light inside the buildings, this study aimed to analyze the interference of the built environment in the availability of natural light inside of multifamily buildings on the north coast Maceio, using parameters established by urban regulations. The present paper is an exploratory study that composes a dissertation in progress. The methodology consisted of a case study, in which simulations were made in the software TropLux 6 to study the influence of all the variables related to the environment of buildings in urban area. Among the results, it was found that the presence of the obstructing building can decrease by $40 \%$ in average global illuminance west oriented window and at least this decrease can be $15 \%$ in the targeted opening to the south. These data show that depending on the parameters adopted surrounding buildings may negatively affect the level of illuminance within the room. Therefore urban regulations of Maceió should include more specifically the use of natural resources such as sunlight. In order to promote the reduction of energy consumption by the artificial lighting systems especially in the more densely populated urban areas.
\end{abstract}




\section{INTRODUÇÃO}

Atualmente, mediante a necessidade de conservação de energia, o conceito de eficiência energética vem se destacando na construção civil. Surge assim uma maior preocupação com a adaptação das edificações às condições climáticas do local e a garantia de acesso à luz solar no meio urbano. $\mathrm{O}$ aproveitamento da luz natural se apresenta como uma alternativa econômica para a iluminação do interior das edificações. A integração entre a luz natural e a artificial minimiza o desperdício de energia elétrica e os gastos com instalação e manutenção de equipamentos.

Entretanto, com o aumento da urbanização e consequentemente, a crescente verticalização nas cidades, a disponibilidade de luz no ambiente interno tem sido prejudicada ou desconsiderada no projeto arquitetônico e urbanístico. Estudos como o de Li (2008), Ng e Wong (2004) determinaram variáveis que interferem na iluminação natural no ambiente interno. Oral et al (2004) classificaram os parâmetros em dois grupos: os relacionados com o ambiente externo, que estão além do controle do projetista, no caso a radiação solar e o nível de iluminação externa e o outro grupo de variáveis relacionadas com o ambiente construído, que pode ser projetado e construído pelo homem. As regulamentações urbanas que devem ordenar e organizar o crescimento da cidade, visando o bem estar do usuário e menor impacto ambiental, têm considerado de forma superficial a relação das edificações com o clima local. Desse modo, o planejamento urbano das cidades brasileiras necessita de parâmetros edilícios e urbanos específicos baseados na obtenção de conforto luminoso, térmico e acústico.

Algumas das variáveis externas, determinadas pela regulamentação urbana, que podem interferir no conforto ambiental no interior das edificações são as seguintes: largura e orientação da via, altura das edificações e afastamento entre as construções. Estes parâmetros já foram estudados em relação à disponibilidade de luz no ambiente interno por Scalco (2010) e Laranja (2010) entre outros pesquisadores, verificando a relevância desses aspectos para o planejamento das cidades.

No caso da cidade de Maceió, por estar localizada em uma zona tropical úmida e receber uma grande quantidade de radiação solar durante todo o ano, torna-se propícia a utilização de estratégias para o aproveitamento da iluminação natural na arquitetura. Entretanto, o Plano Diretor de Maceió (MACEIÓ, 2005), complementado pelo Código de Urbanismo e Edificações da cidade de Maceió, (Lei Municipal 5.593/07) (MACEIÓ, 2007), não contemplam de maneira específica o uso dos recursos naturais como a luz solar, o que pode causar o aumento do consumo energético principalmente nas áreas mais adensadas, por meio de sistemas artificiais de iluminação e climatização.

Tendo em vista que prédios mais altos podem afetar a disponibilidade de luz natural no interior das edificações, este trabalho tem como objetivo analisar a interferência do entorno construído na disponibilidade de luz natural no interior de edifícios multifamiliares no litoral norte de Maceió, a partir de parâmetros estabelecidos pela regulamentação urbana.

\section{REVISÃO BIBLIOGRÁFICA}

Para o desenvolvimento do projeto arquitetônico com o aproveitamento da iluminação natural é importante conhecer entre outros fatores as condições luminosas da abóbada celeste do local, influenciada inicialmente pela condição de céu predominante. Outro fator que também pode interferir na obtenção de luz natural no ambiente interno é a 
configuração morfológica do seu entorno imediato natural e construído (MAJOROS, 1998). Além da orientação, as dimensões e formas da edificação.

A luminância do céu não é constante. A posição do sol, as nuvens, a composição da atmosfera interferem no processo de difusão da luz, definindo assim a configuração do céu ou sua distribuição de luminância. Sedo assim, é comum a consideração de três tipos de céu: céu claro, céu nublado e céu parcialmente nublado.

Tendo como foco a cidade de Maceió, que apresenta uma variação entre esses três tipos de céu, com predominância do céu parcialmente nublado na maior parte do tempo, a determinação dos 16 tipos de céu padronizados da Comissão Internacional de Iluminação (CIE, 2003) é importante para o estudo da iluminação natural no clima tropical úmido, pois oferecem modelos adequados para simular o céu parcialmente nublado. Nikiforiadis e Pitts (2003) ressaltam que o aspecto mais evidente e importante da simulação da luz natural é a natureza variável da fonte. Pois, os resultados estão vinculados a uma previsão de condições externas que variam de acordo com a hora do dia, a data do ano, e com o tempo.

Entretanto o efeito da obstrução apresenta uma dualidade. A princípio, as obstruções podem refletir a luz de outras partes do céu para o ambiente interno. Por outro lado, pode parecer desfavorável para a disponibilidade de luz natural no ambiente, como destaca Li (2008), as construções localizadas próximas uma das outras, além de impedirem a incidência da luz direta do Sol, também obstruem partes da abóbada celeste reduzindo os níveis de iluminação natural. Principalmente nas unidades localizadas nos pavimentos inferiores.

A orientação das aberturas de um edifício também tem grande influência na iluminação natural do seu interior. Para qualquer orientação as janelas oferecem luz natural útil para a iluminação dos ambientes internos. Entretanto, com o adequado tratamento para cada orientação pode-se obter melhores resultados luminosos. Unver et al (2003) em seu estudo aponta a orientação da fachada um dos parâmetros básicos a serem levados em consideração para a disposição da iluminação natural no ambiente.

\section{MÉTODO}

O método adotado consistiu em um estudo de caso, a partir da utilização da simulação computacional para gerar dados e possibilitar a análise comparativa da influência de um conjunto de variáveis, relacionadas ao entorno das edificações no espaço urbano, na disponibilidade de luz natural no interior dos ambientes. Para realização do presente estudo, considerou-se a iluminância média anual, a fim de analisar comparativamente os dados resultantes das simulações de cenários semelhantes. A aplicabilidade de tal parâmetro pode ser observada em trabalhos anteriores a exemplo de Laranja (2010).

A primeira parte define as características do ambiente a ser estudado. Em seguida é descrito o software selecionado para realizar as simulações computacionais. Por fim, baseados nos instrumentos normativos do município, o Código de Urbanismo e Edificações e o Plano Diretor, são estabelecidos os parâmetros que foram estudados.

\subsection{Características do ambiente de referência}

Inicialmente, para realização do trabalho, foi escolhido como objeto de estudo a edificação multifamiliar, em razão do crescimento urbano no litoral norte e a liberação do gabarito das edificações nessa área. Para simular a disponibilidade de iluminação natural nesse tipo de edificação foi definido um ambiente interno base e sua abertura, 
tomando-se como referência o Código de Urbanismo e Edificações da cidade de Maceió-AL, Lei $\mathrm{n}^{\circ}$ 5354/2007 (MACEIÓ, 2007), em conjunto com a Norma de Desempenho para Edifícios Habitacionais (NBR 15.575, 2013) e com as diretrizes do Regulamento Técnico da Qualidade para o Nível de Eficiência Energética de Edificações Residenciais (RTQ-R) (BRASIL, 2012).

O ambiente escolhido é de uso prolongado (quarto e/ou sala) e apresenta as seguintes dimensões: $4 \mathrm{~m}$ de largura por $6 \mathrm{~m}$ de profundidade e parede com $15 \mathrm{~cm}$ de espessura. O que totaliza uma área de $24 \mathrm{~m}^{2}$. Em relação às características dos materiais internos, a refletância adotada para o teto foi de 0,88 (branco), a parede com refletância de 0,65 (amarelo claro) e por último o piso com refletância média 0,3 , considerando a presença do mobiliário. Apesar de a edificação possuir múltiplos pavimentos, será tido como referência o ambiente localizado no primeiro pavimento, por representar a situação menos beneficiada quanto à incidência de luz natural no seu interior, devido à presença de obstruções (edificações) externas.

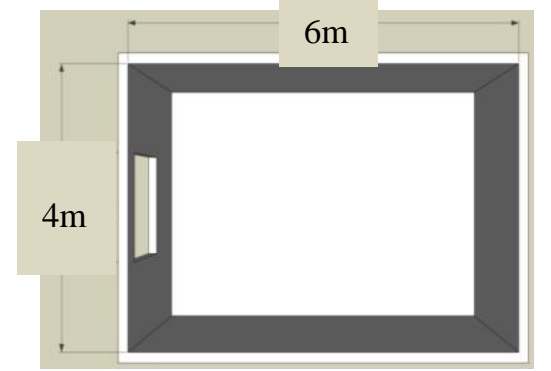

(a)

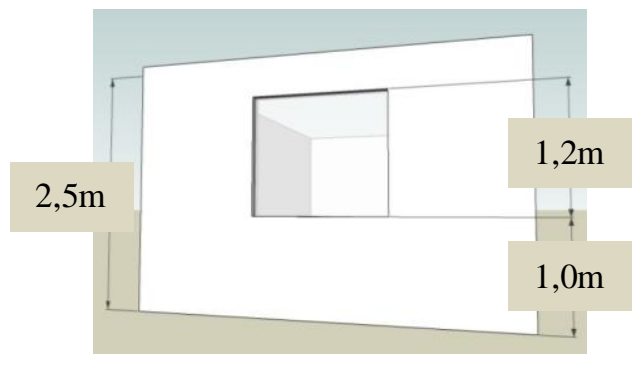

(b)

Figura 1: Perspectiva vista superior (a) e perspectiva vista frontal (b) do ambiente interno base para simular a disponibilidade de iluminação natural.

De acordo com o RTQ-R (BRASIL, 2012), o acesso à iluminação natural em ambientes de permanência prolongada deve ser garantido por uma ou mais aberturas para o exterior. A soma das áreas de aberturas para iluminação natural de cada ambiente deve corresponder a no mínimo $12,5 \%$ da área útil do ambiente. Se esta área for superior a $15,00 \mathrm{~m}^{2}$, o pré-requisito deve ser atendido para $15,00 \mathrm{~m}^{2}$. A área restante não precisa ser contabilizada. Deste modo, a abertura, localizada na parede de menor dimensão, apresenta as seguintes dimensões: largura de $1,57 \mathrm{~m}$, altura de $1,20 \mathrm{~m}$ e peitoril a $1,00 \mathrm{~m}$ do piso. A área da janela, que totaliza $1,88 \mathrm{~m}^{2}$, será fechada por um vidro transparente simples, material frequentemente adotado nas edificações de Maceió.

\subsection{Software escolhido}

A estimativa dos índices de iluminância para a iluminação natural foi realizada através de simulação no software TropLux 6.0.15 (CABÚS, 2014), visto que sua principal finalidade é a de simular o desempenho da iluminação natural no interior do ambiente. Em relação ao espaço interno, com esta ferramenta, é possível representar variados tipologias arquitetônicas, determinar a localização e dimensionamento das aberturas em qualquer parede e definir a refletância das superfícies internas. Quanto aos elementos do entorno da edificação, o programa permite trabalhar com a geometria urbana, podendo determinar a posição e dimensões das obstruções e características das superfícies refletoras.

\subsection{Estudo paramétrico, baseado nos instrumentos normativos do município}

No meio urbano é importante que os instrumentos normativos da cidade, que tem como objetivo ordenar e organizar o seu crescimento, determinem parâmetros que garantam o 
acesso à iluminação natural no interior dos ambientes. $\mathrm{O}$ presente trabalho, que tem como objeto de estudo uma área com perspectivas de adensamento vertical, toma como referências os parâmetros impostos pelo Código de Urbanismo e Edificações da cidade de Maceió, Lei n 5354/2007 (MACEIÓ, 2007), para a Zona Residencial 5 (ZR-5). Os parâmetros selecionados são os seguintes: largura das vias, orientação da abertura e altura das edificações obstruidoras.

No parâmetro largura da via foram analisados todos os tipos de vias determinadas pelo Código, visto que é possível a futura ocorrência de todas elas nesta área. As quatro dimensões de vias são as seguintes:

- $12 \mathrm{~m}$ de largura, para vias com até $200 \mathrm{~m}$, sendo $8 \mathrm{~m}$ para a pista de rolamento e $2 \mathrm{~m}$ de passeio de cada lado;

- $14 \mathrm{~m}$ de largura, para vias acima de $200 \mathrm{~m}$ até $600 \mathrm{~m}$, sendo $9 \mathrm{~m}$ para a pista de rolamento e 2,5 $\mathrm{m}$ de passeio de cada lado;

- $18 \mathrm{~m}$ de largura, para vias acima de $600 \mathrm{~m}$ até $800 \mathrm{~m}$, sendo $12 \mathrm{~m}$ para a pista de rolamento e $3 \mathrm{~m}$ de passeio de cada lado.

- 29 m de largura, para vias acima de $800 \mathrm{~m}$, sendo o canteiro central de $5 \mathrm{~m}$ duas pistas de rolamento de $9 \mathrm{~m}$ e $3 \mathrm{~m}$ de passeio de cada lado, incluindo a ciclovia.

Para avaliar o desempenho luminoso em diferentes orientações, foi adotada a orientação da via Leste - Oeste, a qual possibilita a orientação da abertura para Norte e para Sul e a orientação da via Norte - Sul, que possibilita a orientação da abertura para Oeste e para Leste. Isso permitirá visualizar como a disponibilidade de luz no ambiente interno se comporta para cada orientação e na presença de obstruções quais das orientações apresentam maior interferência na quantidade de luz natural.

Para avaliar a interferência da altura das edificações obstruidoras na iluminação natural de espaços internos, foi adotada a ocupação do solo prevista no Código de Urbanismo e Edificações da cidade de Maceió. De acordo com a Zona Residencial 5, em se tratando da implantação na gleba ou no lote de uma edificação multifamiliar com três ou mais pavimentos aplica-se o Uso Residencial 5 (UR-5). Com isso, três taxas de ocupação são permitidas: de $50 \%$, $35 \%$ e $20 \%$. Para este trabalho serão consideradas estas três taxas de ocupação e os parâmetros correspondentes, que são os seguintes:

- $\mathbf{5 0 \%}$ taxa de ocupação: altura máxima da edificação 10 pavimentos, totalizando a altura de $32 \mathrm{~m}$.

- $\mathbf{3 5 \%}$ taxa de ocupação: altura máxima da edificação 15 pavimentos, totalizando altura de $45 \mathrm{~m}$.

- $\mathbf{2 0 \%}$ taxa de ocupação: altura máxima da edificação 20 pavimentos, totalizando altura de $58 \mathrm{~m}$.

Vale ressaltar que no presente trabalho não será considerada a variação do nível do terreno. Tanto a edificação estudada, quanto as obstruções externas estão num plano de mesmo nível, o que possibilita a análise comparativa entre os parâmetros.

As Figura (a) e (b) ilustram a planta baixa e o perfil do cenário que serviu de base para os demais parâmetros adotados. O terreno foi fixado nas dimensões de $51 \mathrm{~m}$ x $45 \mathrm{~m}$, total de $2.295 \mathrm{~m}^{2}$. As dimensões das edificações foram calculadas a partir a taxa de ocupação e coeficiente de aproveitamento, fixando a largura da fachada frontal em 30 $\mathrm{m}$, largura máxima permitida. Via com a menor largura de $12 \mathrm{~m}$. Os afastamentos frontais correspondem à altura máxima permitida para cada taxa de ocupação. 


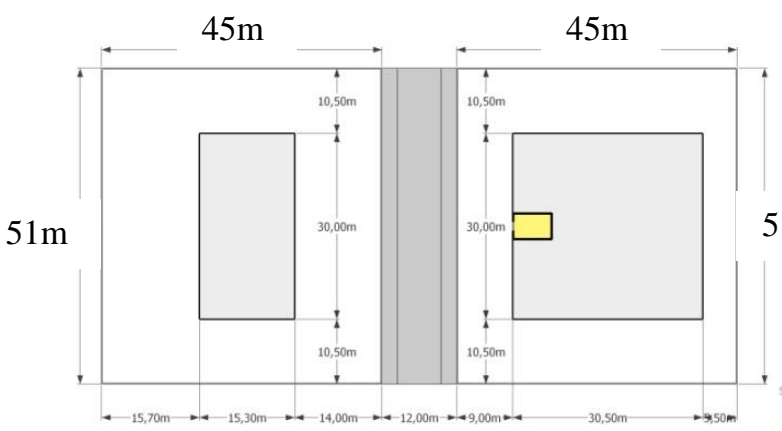

(a)

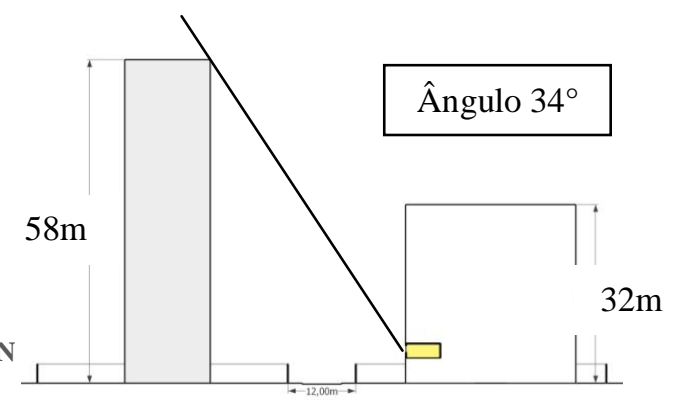

(b)

Figura 2: Ilustração da planta-baixa (a) e ilustração do perfil (b) do cenário que serviu de base para os demais parâmetros.

\subsection{Simulações computacionais}

Foram fixados para todas as simulações no programa TropLux os mesmos parâmetros de local, tipo de céu, período do dia e do ano, pontos para aferição da iluminância e características do plano de trabalho.

Para avaliar a disponibilidade de luz natural ao longo do dia e por considerar as diferentes trajetórias solares ao longo do ano, foi adotado para simulação todos os dias do ano e 9 horas do dia, no período entre 8 h e 16 h (horário solar). Horário que há maior contribuição do Sol em Maceió para iluminação no interior dos ambientes.

A cidade escolhida foi Maceió (Latitude $9^{\circ} 40^{\prime} \mathrm{S}$, Longitude $35^{\circ} 42^{\prime} \mathrm{O}$ ), caracterizada pelo clima tropical úmido, céu parcialmente nublado na maior parte do ano e abundante disponibilidade de luz natural junto à radiação direta do Sol. A versão 6.0 do software TropLux disponibiliza, além de 15 céus padrão CIE, uma opção chamada céu dinâmico, a qual é baseada na variação do céu de Maceió durante todo o ano. Ao considerar as possibilidades oferecidas pelo programa, a metodologia utilizada neste trabalho utilizou o céu dinâmico.

Não é possível determinar uma altura para área de trabalho que seja comum às diferentes atividades desempenhadas no interior dos ambientes desse tipo de edificação. Com isso, foi adotada, conforme a NBR ISO/CIE 8995-1 (ABNT, 2013), a altura para o plano de trabalho de $75 \mathrm{~cm}$. Para aferição dos valores de iluminância, esta norma determina que a malha seja composta por pontos a cada $1 \mathrm{~m}$ da maior dimensão da sala, o que totaliza 6 pontos. Entretanto, para uma maior precisão nos resultados foi determinada uma malha com 24 pontos distribuídos igualmente por todo o ambiente, ou seja, 1 ponto a cada $1 \mathrm{~m}^{2}$.

\section{RESULTADOS E DISCUSSÃO}

A partir dos resultados obtidos através das simulações no programa Troplux, foi possível analisar comparativamente a interferência dos seguintes parâmetros: orientação, largura de via e altura da edificação obstruidora na disponibilidade de luz natural no interior do ambiente.

\subsection{Parâmetro: Largura das Vias}

Conforme observado no Gráfico 1, nos cenários que o ambiente está orientado para o sul, o acréscimo na quantidade de luz natural no interior do ambiente foi discreto, inclusive ao se comparar ao crescimento de $1,75 \%$ quando aumenta a via de $12 \mathrm{~m}$ para $14 \mathrm{~m}$ e apenas $1,42 \%$ ao aumentar a via de $14 \mathrm{~m}$ para $18 \mathrm{~m}$. 


\section{Gráfico 1 - Acréscimo da iluminância média anual com o aumento da largura da via para a janela orientada para o sul e oeste.}

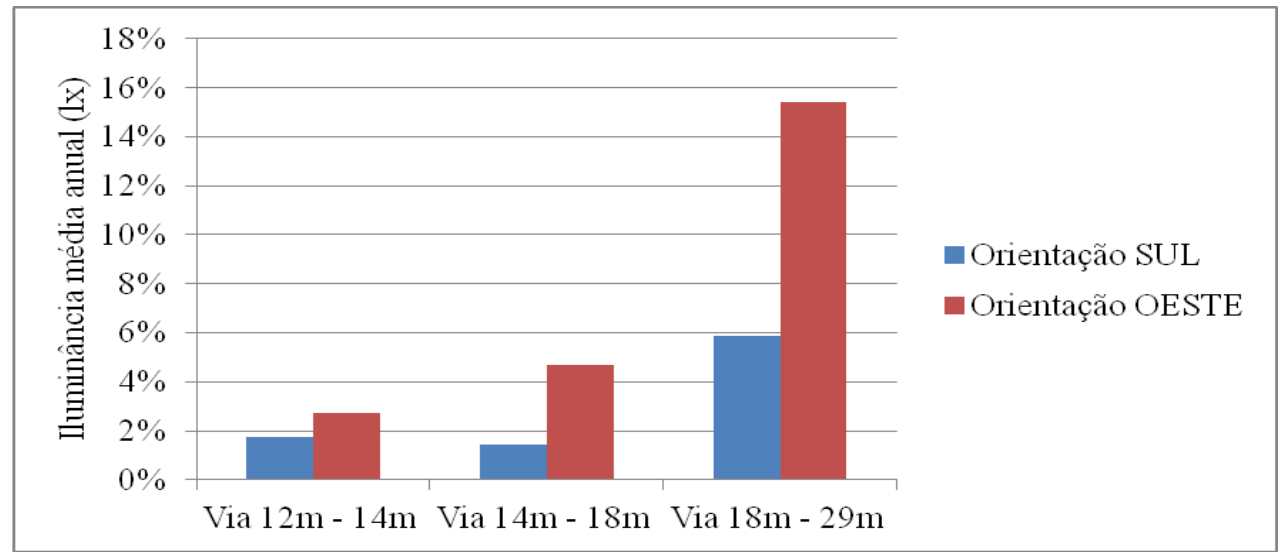

Fonte: Produção do autor (2014).

Com o aumento da via, o que resulta num maior distanciamento entre o ambiente e a edificação obstruidora, o nível de iluminação natural interna foi crescente em todas as orientações, como esperado. Principalmente nos cenários nos quais o ambiente está orientado para oeste (Gráfico 1), que apresentaram uma variação mais significativa da iluminância, chegando a um acréscimo de $15,42 \%$ com o aumento da largura da via de $18 \mathrm{~m}$ para de $29 \mathrm{~m}$.

Quando comparado os cenários com as obstruções separadas por diferentes larguras de vias ao cenário sem obstrução, conforme a Tabela 1, nota-se que a presença da obstrução pode diminuir em até $40,43 \%$ a iluminância global média no ambiente orientado para oeste, considerando a via de $12 \mathrm{~m}$, e no mínimo $15,25 \%$ no espaço orientado para o sul, considerando a via com $29 \mathrm{~m}$ de largura. Isso indica que, independente da orientação, para todas as larguras de via há interferência na iluminância média anual no interior do ambiente, principalmente na via de menor dimensão.

Tabela 1: Diminuição da iluminância média anual do Cenário sem obstrução para o Cenário com obstrução.

\begin{tabular}{c|c|c}
\hline Orientação & $\begin{array}{c}\text { Cenário sem obstrução x } \\
\text { Cenário com obstrução }\end{array}$ & $\begin{array}{c}\text { Diminuição (\%) da } \\
\text { iluminância média anual }\end{array}$ \\
\hline Sul & Cenário Tipo 0 x V.01 - 10 pav. - via 12 m & $22,70 \%$ \\
\hline Sul & Cenário Tipo 0 x V.04 - 10 pav. - via 29 m & $15,25 \%$ \\
\hline Oeste & Cenário Tipo 0 x V.01 - 10 pav. - via 12 m & $40,43 \%$ \\
\hline Oeste & Cenário Tipo 0 x V.04 - 10 pav. - via 29 m & $24,05 \%$ \\
\hline
\end{tabular}

Fonte: Produção do autor (2014).

\subsection{Parâmetro: Altura da Edificação Obstruidora}

Observou-se que com o aumento da altura da obstrução, mesmo que juntamente com o aumento do afastamento frontal, o ângulo de céu visível foi diminuindo e o nível de iluminação natural também diminuiu no interior do ambiente. Conforme se verifica no Gráfico 2, em relação à orientação oeste, observa-se a redução de $16,34 \% \%$, com a alteração de 10 pavimentos para 15 pavimentos, além disso, há a redução de $18,84 \%$ ocasionada pela alteração de 10 pavimentos para 20 pavimentos. Para a orientação sul, esta redução é a menos significativa. 


\section{Gráfico 2 - Diminuição da iluminância média anual com o aumento da edificação obstruidora, para janela orientada para oeste e sul.}

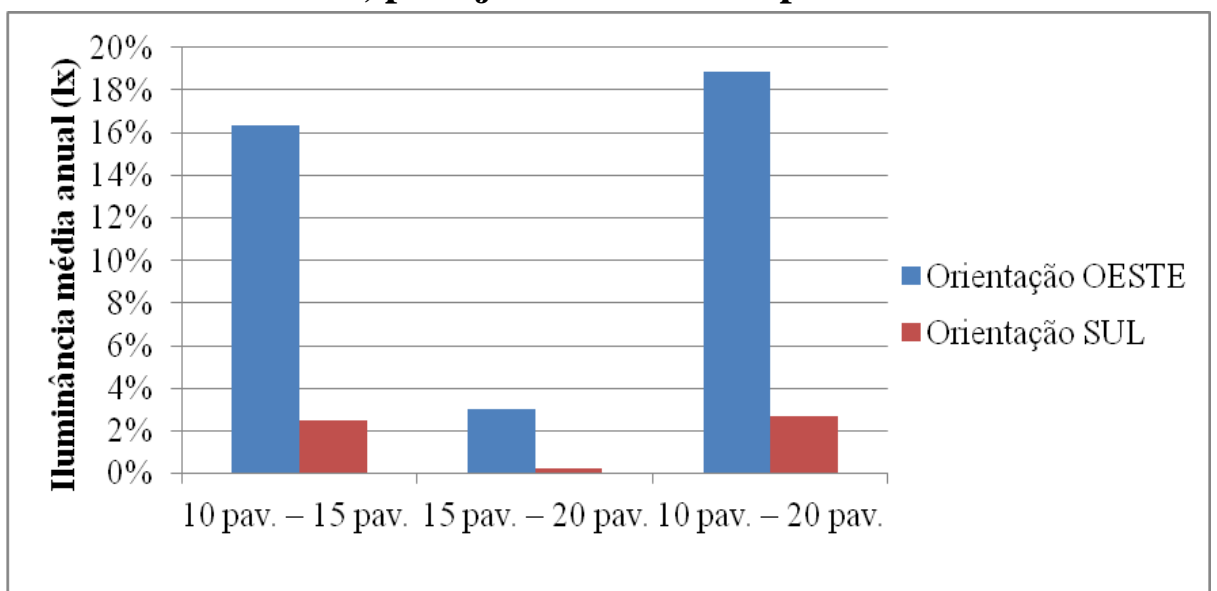

Fonte: Produção do autor (2014).

Diante dos dados apresentados, observa-se que os afastamentos mínimos determinados pelo Código de Urbanismo e Edificações da cidade de Maceió, (Lei Municipal 5.593/07) (MACEIÓ, 2007), para as edificações de 15 e 20 pavimentos não são suficientes para evitar a alteração da iluminância no interior do ambiente. Exceto quando a janela está orientada a sul, pois os três ambientes apesar de possuírem obstruções com alturas diferentes, permanecem com valores próximos de iluminância média anual.

\subsection{Parâmetro: Orientação da Abertura}

Nesse estudo, verifica-se que tanto a alteração da largura da via, como com a alteração da altura das obstruções o acréscimo ou decréscimo da iluminância média anual varia de acordo com a orientação do ambiente. Em ambas as situações, a influência da orientação no aumento do nível de iluminação natural no interior do ambiente é maior para o ambiente orientado a norte. Em seguida, tanto na orientação leste como oeste, os níveis de iluminação natural se mantiveram próximos. Os cenários com o ambiente orientado para o sul, apesar de apresentarem os menores valores de iluminância média anual, atingem elevados níveis de iluminação. Os

Gráfico ilustram respectivamente o efeito da largura da via e da altura das edificações obstruidoras sobre a iluminância média anual no ambiente interno, analisado nas quatro orientações.

\section{Gráfico 3: Iluminância média anual no interior do ambiente em função da largura} de via.

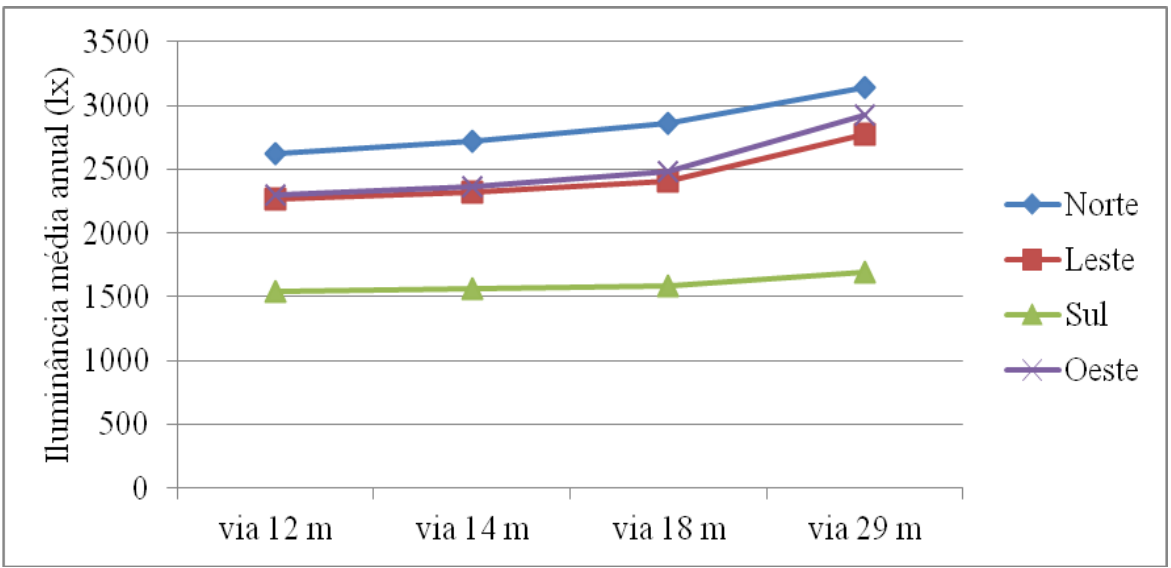

Fonte: Produção do autor (2014). 


\section{Gráfico 4: Iluminância média anual no interior do ambiente em função da altura da edificação obstruidora.}

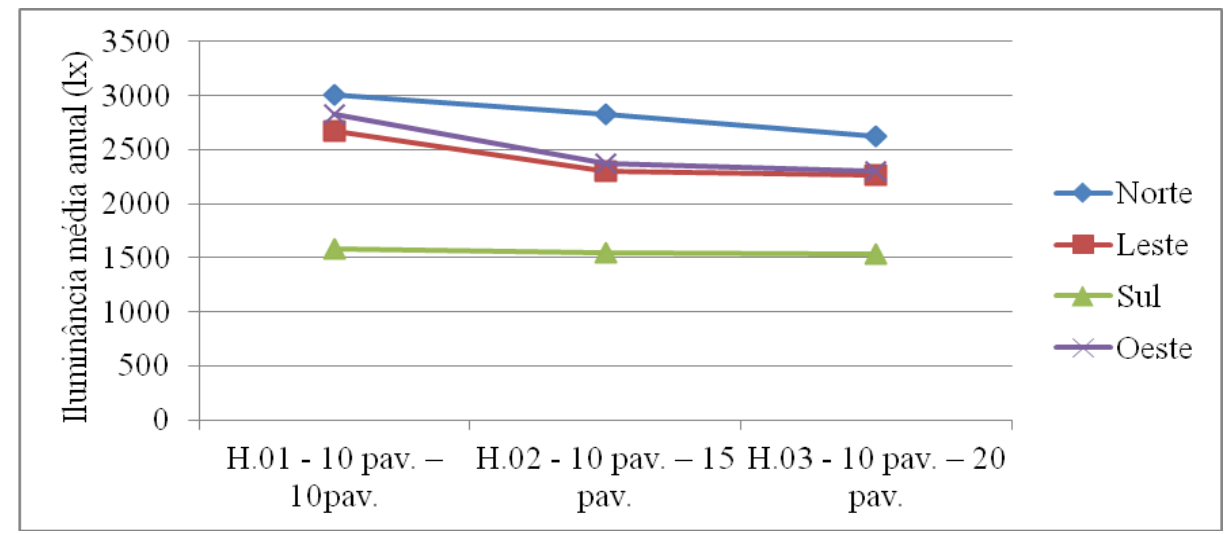

Fonte: Produção do autor (2014).

A orientação sul, provavelmente por ter menos incidência de luz solar direta durante o ano, geralmente apresenta pouca variação dos valores de iluminância média anual entre as diferentes situações de obstrução. Isso indica que nas outras orientações, que apresentam variação no nível de iluminação natural no interior do ambiente para os diferentes tipos de obstrução, a presença da edificação obstruidora pode impedir a incidência de radiação direta no ambiente.

\section{CONCLUSÕES OU CONSIDERAÇÕES FINAIS}

O presente trabalho tratou da contribuição do estudo da interferência de parâmetros urbanos na disponibilidade de luz natural no interior de edifícios multifamiliares, através de simulações no programa TropLux. Comprovou-se que todos os parâmetros analisados apresentaram influência no nível de iluminação no ambiente interno.

Constatou-se que o aumento da largura da via implica no acréscimo dos valores de iluminância média anual. Entretanto, mesmo na maior largura de via, que é de $29 \mathrm{~m}$, a presença da obstrução diminui a incidência de luz natural no ambiente interno. Verificou-se que a presença da edificação obstruidora pode diminuir em até $40 \%$ a iluminância global média no ambiente orientado para oeste e que no mínimo essa diminuição pode ser de $15 \%$ no espaço orientado para o sul.

Esperava-se que, apesar do aumento da altura da edificação obstruidora, o afastamento frontal, indicado pelo Código de Urbanismo e Edificações da cidade de Maceió (Lei Municipal 5.593/07) (MACEIÓ, 2007) para cada taxa de ocupação permitida, fosse suficiente para garantir níveis aproximados de iluminação natural no interior do ambiente para todas as situações de obstrução estudadas. Entretanto, observou-se que com o aumento da altura da edificação obstruidora houve redução dos valores de iluminância no interior do ambiente, exceto para orientação da janela a sul.

Em ambos os casos, verificou que a orientação é importante para a iluminância no ambiente interno, as orientações norte, oeste e leste apresentaram maiores níveis de iluminação natural do que a orientação sul. Porém, a abertura orientada a sul apresentou valores elevados de iluminância, que podem satisfazer a iluminação do ambiente.

A partir dos resultados encontrados, foi constatada a importância da contribuição do plano diretor e demais regulamentações no favorecimento da disponibilidade de iluminação natural, através da indicação de parâmetros urbanos eficazes que assegurem o acesso à iluminação natural a todos os usuários. Vale ressaltar a necessidade em atentar para as decisões do projeto arquitetônico quanto a sua adequação ao entorno 
construído de forma à aproveitar da melhor forma a disponibilidade da luz natural no interior do ambiente, levando sempre em consideração a orientação das aberturas.

\section{AGRADECIMENTOS}

A CAPES, pelo apoio recebido.

\section{REFERÊNCIAS}

ASSOCIAÇÃO BRASILEIRA DE NORMAS TÉCNICAS - ABNT. NBR 15575: Edificações Habitacionais - Desempenho - Parte 1: Requisitos gerais. Rio de Janeiro, 2013.

2013.

NBR 8995-1: Iluminação de ambientes de trabalho - Parte 1: Interior. Rio de Janeiro,

BRASIL. Ministério do Desenvolvimento, Indústria e Comércio Exterior. Instituto Nacional De Metrologia, Normalização e Qualidade Industrial - INMETRO. Portaria n. ${ }^{\circ}$ 18, de 16 de janeiro de 2012. Rio de janeiro, 2012.

CABÚS, R. C. TropLux, versão 6.0.15, Maceió: Grilu, 2014.

CIE - COMMISSION INTERNATIONALE L'ACLAIRAGE. Spatial distribution of daylight - CIE standard general sky. Publication CIE S 011/E:n2003. Viena, Áustria, 2003.

LARANJA, Andréa C. Parâmetros urbanos e a disponibilidade de iluminação natural no ambiente interno. Rio de Janeiro, 2010. Tese (Doutorado em Arquitetura e Urbanismo). Programa de Pós-Graduação da Faculdade de Arquitetura e Urbanismo. Universidade Federal do Rio de Janeiro.

LI, Danny H.W; TSANG, Ernest K.W. An analysis of daylighting performance for office buildings in Hong Kong. Building and Environment, v. 43, issue 9, p. 1446-1458, 2008.

MACEIÓ, Lei $\mathbf{n}^{\circ} \mathbf{5 5 2 8}$ de dezembro de 2005. Institui o Plano Diretor de Maceió, estabelece diretrizes gerais de política de desenvolvimento urbano e dá outras providências. 2005. Disponível em: <http://www.maceio.al.gov.br> Ultimo acesso em 10 de setembro de 2013.

MACEIÓ, Lei Municipal $\mathbf{N}^{\circ} \mathbf{5 . 5 9 3}$, de 08 de Fevereiro de 2007. Institui o Código de Urbanismo e Edificações do Município de Maceió. Disponível em <http://www.maceio.al.gov.br> Último acesso em 10 de setembro de 2013.

MAJOROS, András. Daylighting. PLEA Notes, Note 4. PLEA in Association with Department of Architecture, the University of Queensland. Edited by S.V.Szokolay, 1998.

NG, E.; WONG, N. H. Better daylight and natural ventilation by design. In: INTERNATIONAL CONFERENCE ON PASSIVE AN LOW ENERGY ARCHITECTURE, 21., 2004, Eindhoven, Netherlands. Proceedings... Eindhoven: PLEA, 2004.

NIKIFORIADIS, F.; PITTS, A. 3D digital geometric reconstruction of the urban environment for daylight simulations studies. In: INTERNATIONAL BUILDING SIMULATION CONFERENCE, 8., Eindhoven, Netherlands, 2003. Proceedings...Eindhoven: IBPSA, 2003.

ORAL, G. K.; YENER, A. K.; BAYAZIT, N. T. Building envelope design with the objective to ensure thermal, visual and acoustic comfort conditions. Building and Environment, v.39, issue 3, p. 281-287, 2004.

SCALCO, Veridiana A. Método para a avaliação dos impactos de edificações sobre a iluminação natural e insolação em vizinhanças urbanas. Florianópolis, 2010. Tese (Doutorado em Engenharia Civil). Programa de Pós-Graduação em Engenharia Civil. Universidade Federal de Santa Catarina.

ÜNVER, R.; ÖZTÜRK, L.; ADIGÜZEL, S.; ÇELIK, Ö. Effect of the facade alternatives on the daylight illuminance in offices. Energy and Building, v. 35, issue 8, p. 737- 746, 2003. 